\title{
Exploring the potential for private pharmacies to provide family planning services in Senegal
}

\author{
Fatou Mbow \\ Population Council \\ Sara Chace Dwyer \\ Population Council \\ Nafissatou Diop \\ Population Council
}

Follow this and additional works at: https://knowledgecommons.popcouncil.org/departments_sbsr-rh How does access to this work benefit you? Let us know!

\section{Recommended Citation}

Mbow, Fatou, Sara Chace Dwyer, and Nafissatou Diop. 2018. "Exploring the potential for private pharmacies to provide family planning services in Senegal," Synthesis brief. Dakar: Population Council, The Evidence Project. 


\section{Exploring the Potential for Private Pharmacies to Provide Family Planning Services in Senegal}

In Senegal, the National Action Plan for Family Planning (NAPFP) 2012-2015 and the National Strategic Framework for Family Planning 2016-2020 adopted a multi-sectoral approach to broaden access to family planning (FP) services and to reach $45 \%$ modern contraceptive prevalence (mCPR) by 2020 (NAPFP, 2012). The private sector and community actors are key partners with the public sector in implementing this approach. However, private pharmacies have not been actively involved in the provision of FP services due to legal and nonlegal barriers that limit their role to selling contraceptives and providing method-specific advice. As Senegal seeks to involve the private sector in improving access to FP, this study found that the country is in an optimal position to increase the role of private pharmacies in FP, which could contribute to the country reaching its $\mathrm{mCPR}$ goals.

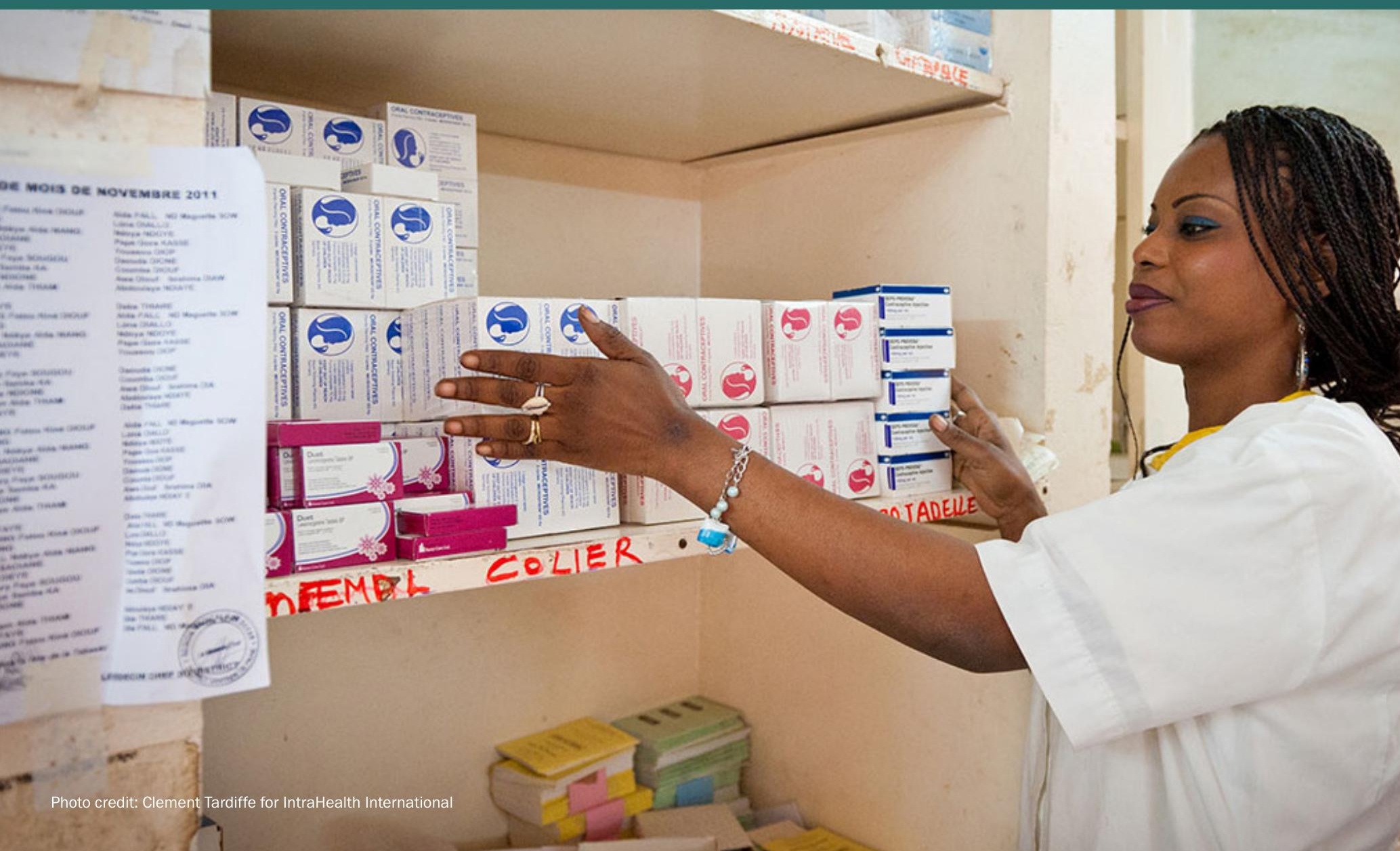


In 2012, the Directorate of Reproductive Health and Child Survival (DRHCS) of the Ministry of Health and Social Action (MHSA) adopted the ambitious National Action Plan for Family Planning (NAPFP) for 2012-2015. One goal is to increase the modern contraceptive prevalence rate (mCPR) from the 2012 rate of $12 \%$ to $27 \%$ in 2015 and to $45 \%$ in 2020 by increasing access to family planning (FP) services. Between 2012 and 2014, the mCPR increased by four percentage points annually, reaching $20 \%$ in 2014 (ANSD and ICF International 2012 and 2015). ${ }^{1}$ The rate of increase began to slow, with the $\mathrm{mCPR}$ only reaching 21\% in 2015 (ANSD and ICF 2016). The unmet need for FP remains high at 25\% among women in union (ANSD and ICF International 2015). A National Strategic Framework for Family Planning (NSFFP) was adopted for 2016-2020, with the same mCPR goal of $45 \%$ by 2020 .

The Population Council conducted an exploratory study in 2015 on the potential role of private pharmacies in the provision of FP services in Senegal. The DRHCS, the U. S. Agency for International Development (USAID) Health Office in Senegal, the Agency for the Development of Social Marketing (ADEMAS), the Ouagadougou Partnership Coordination Unit, the Institute of Population, Development, and Reproductive Health, and the Direction of Pharmacy and Medicine were collaborators. The purpose of this study was to explore the barriers to, and opportunities for, the provision of FP services by private pharmacies.

Evidence from this study supports on-going advocacy efforts for greater involvement of private pharmacies in FP services. The involvement of private pharmacies in FP services is consistent with the multi-sectoral approach promoted by the Government of Senegal. This research was carried out with financial support from USAID through the Evidence Project and the William and Flora Hewlett Foundation.

\section{Methodology}

This study was conducted in the Dakar region and combined several data collection methods to explore the role of private pharmacies in FP provision. There were four components of the study.

1 Continued Demographic and Health Study.
- A literature review of the legal aspects. The Population Council and the Direction of Pharmacies and Medicine analyzed relevant laws and regulations to identify arguments in favor of, and against, the provision of FP services by private pharmacies, and to suggest necessary policy revisions that would allow private pharmacies to provide FP services. The review consisted of an inventory and analysis of the broad legislative and regulatory texts governing the private sector, and private pharmacies specifically (Mbow, Fall, Diop, and Chace Dwyer 2018).

- A literature review on the nonlegal aspects. The Institute of Population, Development, and Reproductive Health reviewed evidence on the non-legal aspects related to the role of private pharmacies in FP services. The review consisted of identifying and analyzing journal articles, reports, and other program documents related to this topic from Senegal and other countries in Africa and Asia (Diaby, Mbow, Sall, and Chace Dwyer 2018).

- Secondary analysis of ADEMAS data. The Population Council and ADEMAS analyzed survey/ evaluation data from private pharmacies to gain better insight into the experiences of FP provision by pharmacies (Mbow, Diallo, Diop, Kane, Sarr, and Chace Dwyer 2017).

- Qualitative research. The Population Council conducted in-depth interviews (IDI) with 27 FP stakeholders in the Dakar region and 30 private pharmacists in the cities of Dakar, Guediawaye, and Pikine to understand perceptions, opportunities, challenges, and possible solutions for greater private pharmacy involvement in FP provision. The IDIs with private pharmacies were supplemented by data collection on counseling and sales of FP products at private pharmacies, where possible (Mbow, Diop, Chace Dwyer, Ndiaye, and Daff 2018).

This brief summarizes the various components, provides an overview of the issues, and outlines the recommendations.

\section{Results}

\section{Family Planning Experience of Private Pharmacies}

In Senegal, as in many countries in the Ouagadougou Partnership, private pharmacies play a minor role 
in FP service provision. Their role is often limited to the sale of FP methods, method-specific advice, and referrals (see Graph 1). Based on the Senegal 3D Approach, Partnership countries have committed to democratizing, de-medicalizing, and decentralizing certain family planning services. This has led to the introduction of task-shifting policies in reproductive health generally, and for FP specifically. Evidence from countries in Asia (Bangladesh, Indonesia, Nepal, and the Philippines) and from African countries outside the Ouagadougou Partnership (Nigeria and Uganda) suggest private pharmacies could play a greater role in directly providing contraceptive methods, such as the pill and/or injectables (Hotchkiss et al. 2011). In Senegal, some pharmacists are already involved in pilot projects to increase service delivery of FP counseling.

\section{Barriers to Family Planning Service Provision by Private Pharmacies in Senegal}

Private pharmacies do not have a major role in the provision of FP services due to multiple factors. The main barriers limiting their participation are legal restrictions. For FP provision, private pharmacies are regulated by the Code of Public Health, the Pharmacists Code of Ethics, Law of Reproductive Health, and pharmaceutical policies regulating drug sales. Many private pharmacists in Senegal consider the texts governing "dispensary pharmacy"2 outdated, including the law from April 15, 1954, (the law specifically refers to the French Code of Public Health) that regulates all health professionals in Senegal. Article 569 from the April 1954 law states that "the operation of a pharmacy is incompatible with the practice of another profession, particularly that of a medical practitioner, a veterinarian, a midwife, or a dentist."

2 Official name to designate private pharmacies in Senegal.

GRAPH 1 METHODS
PROPORTION OF PHARMACIES THAT SELL OR ADMINISTER FAMILY PLANNING

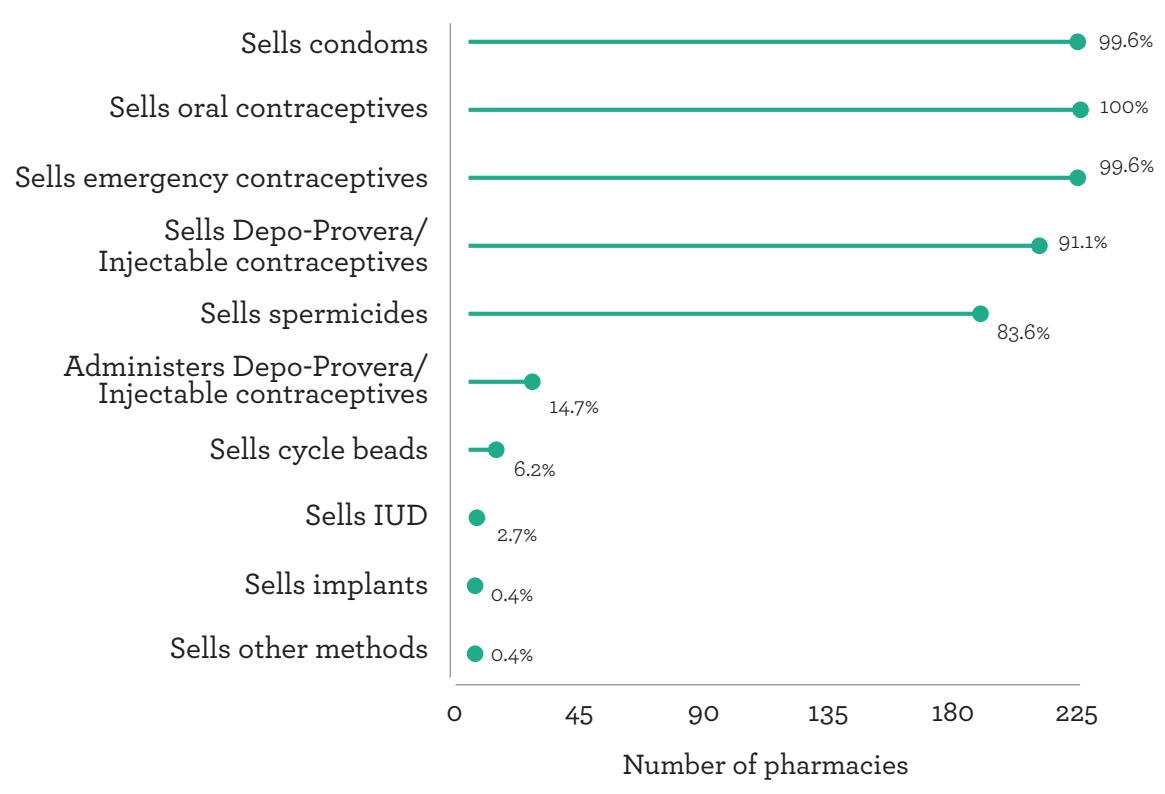

Source: Rapport d'analyse de la PF dans les pharmacies du milieu urbain au Sénégal, 2015

This presupposes that a pharmacist cannot engage in medical procedures (such as injections), which are the purview of health professionals. This provision is corroborated by Article 72 of the 1981 Decree on the Pharmacists Code of Ethics, which states: “...the pharmacist must ensure that consultations or medical procedures are never practiced in the pharmacy by anyone."

Modern contraceptives (excluding condoms, emergency contraceptives and cycle beads), are subject to the regulation of poisonous substanc$\mathrm{es}^{3}$ as with all drugs on Lists I and II and require a prescription. Article 8 of the August 5, 2005 Law on Reproductive Health stresses that pharmacists and other active health workers "must comply with the standards of competence, service protocols, and rules of professional ethics relating to his profession or activity." This suggests that pharmacists have an obligation to abide by the rules established by pharmaceutical regulations and their code of ethics.

Other barriers to pharmacists participating in the delivery of FP counseling and services were identified in this review, including: the lack of, or insufficient, training of pharmacists in contraceptive technolo-

3 Drugs listed on List I: presenting high-level risks. Drugs listed on List II: poisonous substances considered less dangerous. 
gy; insufficient space within pharmacies for private counseling; unavailability of contraceptive products; lack of counseling materials; the high cost of certain brands of FP methods; and some pharmacists' attitudes about clients' age, marital status, or religious beliefs, that influence which services to offer.

\section{Perceptions of Private Pharmacies' Involvement in the Provision of Family Planning Services}

Results from the non-legal review showed perceptions around the potential role of private pharmacies have evolved. In 2012 a Population Council study found some providers (including pharmacists) were reluctant to offer emergency contraception in private pharmacies (Mane, 2012). By 2015, clients, key FP stakeholders, and private pharmacists themselves were more accepting of the idea of offering emergency contraception services in private pharmacies. According to a 2015 MHSA/FHI360 study (Fall, 2015), most private pharmacy staff surveyed expressed an interest in offering FP. Among respondents, 89\% wanted to be trained in FP counseling, and $85 \%$ wanted to be trained how to offer FP methods (Fall, 2015). Almost half of existing private pharmacy clients were interested in obtaining FP services from private pharmacies, with $43 \%$ wanting to purchase oral and $46 \%$ wanting to receive injectable contraceptives. Respondents who expressed an interest in receiving contraceptives from private pharmacies noted that the price of contraceptives sold in the pharmacy would not be an obstacle.

Results from this study's qualitative component showed that most private pharmacists and FP stakeholders were interested in increasing private pharmacies role in FP service delivery, particularly for providing methods such as the pill and injectables, providing client follow-up, and managing client expectations and concerns about contraceptive side effects. This was highlighted by a government official who said:

"I think there are some leaders...who understand FP issues and are ready to support them [private pharmacies]. I also think that the fact that they [private pharmacies] are there every time they are invited to meetings, that they take the floor, that they say what they think, means that they have an interest in it [FP provision] and think they can be useful to people. So, it's something to build upon."

Several views supporting increased involvement of private pharmacies in FP provision emerged in the IDIs and in the nonlegal review. Among the views expressed were that:

- Most FP stakeholders argued that private pharmacies could help improve reproductive health $(\mathrm{RH})$ and FP program performance;

- Some FP stakeholders argued that despite constraints, some private pharmacies already offer FP services;

- Both stakeholders and pharmacists expressed that some FP methods are currently offered by health workers with lower skills than pharmacists (See Graph 2);

- Pharmacists pointed out that they were trained in nursing as part of their university curriculum;

- Some FP stakeholders express that including pharmacies in FP services provision could strengthen public-private partnerships; and

- Certain pharmacies believe that given their privileged relationship with the community, pharmacists could advocate for FP among men in the community.

In addition to the pharmacists and their assistants, many IDI respondents felt that counter agents (who have similar skill levels to community health workers ${ }^{4}$ ) should also provide FP services, provided they are well trained. Respondents said that:

- In many cases, counter agents make up the majority of pharmacy staff;

- Pharmacists are generally absent from their pharmacies;

- Counter agents are most often in contact with people; and

- Most counter agents have experience working in pharmacies and therefore can navigate a variety of situations.

4 New name for community health agents. 


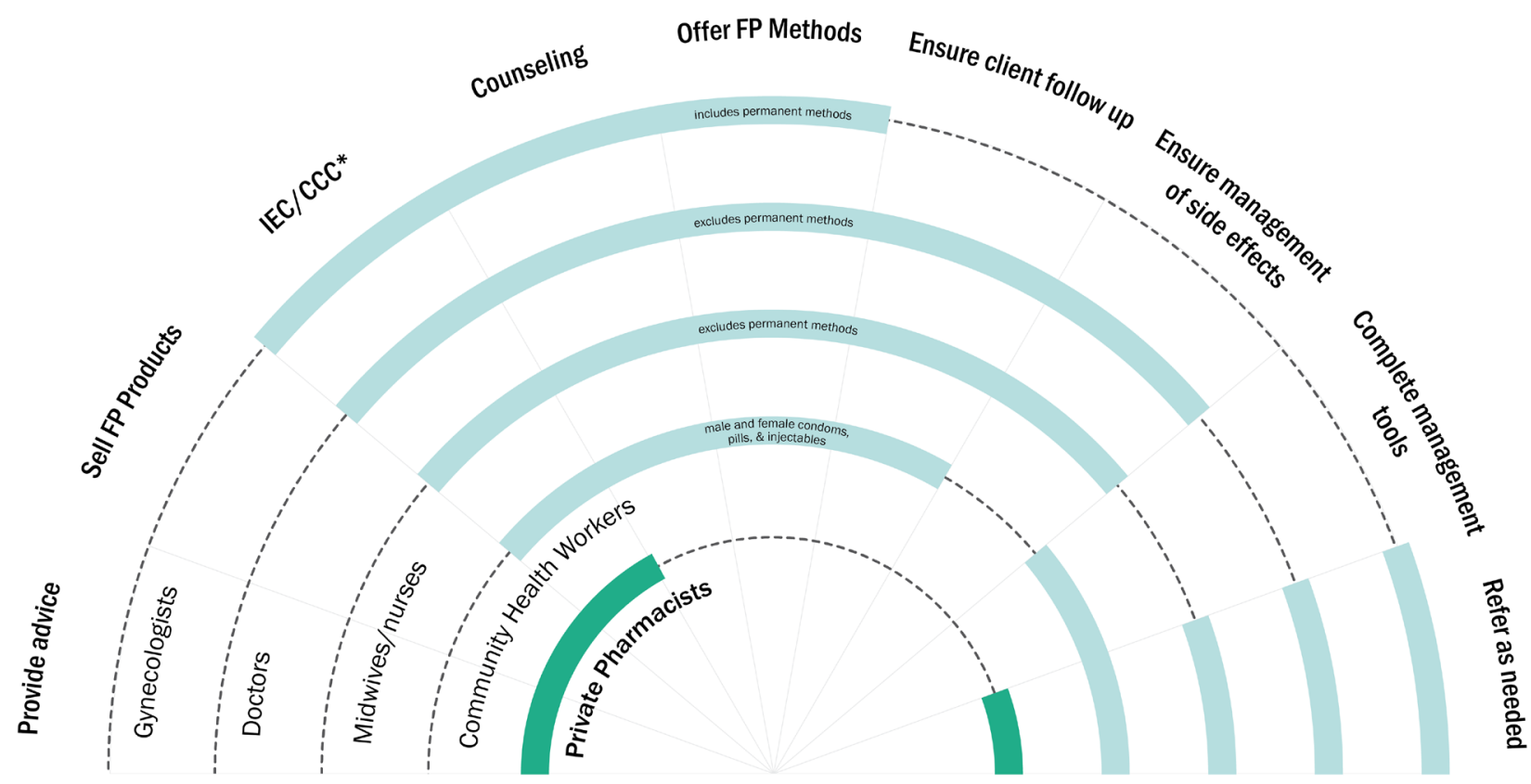

*Information/Education/Communication/Communication for Behavior Change

Source: Politiques, Normes et Protocoles en SR. Partie 2.

One pharmacist said:

"All pharmacy staff and even counter agents should be involved in offering these services. The pharmacist is not always on site and some pharmacies do not have assistants. Some salespersons are highly experienced, with good experience in selling medicines. If they are well trained, they will be able to provide these services."

\section{Opportunities Related to the Provision of Family Planning Services by Private Pharmacies in Senegal}

Based on the legal, non-legal review, and ADEMAS secondary analysis, there are opportunities to increase the contribution of private pharmacies in the provision of FP services. The opportunities include:

- Good geographical coverage of pharmacies, making them excellent service delivery points for FP information and services;
- More than 1,000 pharmacies are spread throughout the country: they are the second largest source of FP methods after public health facilities (DHS-C, 2015);

- Almost all private pharmacies sell oral contraceptives, and 75\% sell injectables (Mbow, 2017);

- Private pharmacy hours of operation and staff availability are flexible for clients in comparison to public health facilities;

- Clients, pharmacists, and FP stakeholders are interested in FP provision by private pharmacies; and

- The de-medicalization of certain FP services, which is part of Senegal's 3D Approach, through task-shifting to community health workers, has already begun in Senegal and in other countries of the Ouagadougou Partnership.

- Senegal has signed on to a range of international and regional agreements and treaties that obligate the government to ensure access to FP/ $\mathrm{RH}$ services for all people, especially for women 


\section{Challenges in Involving Private Pharmacies in the Provision of Family Planning Services}

Transitioning private pharmacies into full-fledged FP service providers will require a large effort on behalf of multiple partners. The following challenges should be addressed for private pharmacies to effectively integrate FP into their existing services

- Revising the legal texts and program documents to allow pharmacy provision of FP services will be time intensive and require inputs from multiple ministerial departments and professional organizations. Evidence is needed for policymakers to clarify what services private pharmacies will be able to offer, under what circumstances, and to decide on the proper regulatory framework.

- To provide existing and new pharmacy staff with technical FP training would require developing in-service curricula, and incorporating FP courses into existing pharmaceutical curricula. This would require a large effort between the pharmacy and $\mathrm{FP} / \mathrm{RH}$ partners to ensure the learning materials are consistent with public sector standards while meeting unique needs of pharmacies.

- According to Senegal's FP policies, health structures are required to have a private space for FP counseling and services. Approximately $25 \%$ of private pharmacies do not have sufficient space (Fall, 2015). Considering that many pharmacists rent their space, those who do not already have a space available will face challenges in complying with this policy.

- In general, private pharmacists view their role from the business lens. To ensure private pharmacies respect individuals' $\mathrm{RH}$ rights will require sensitizations to inform pharmacists about national FP strategies, their potential contribution in increasing people's access to FP information and services, while also benefiting their business.

- The MHSA wants accurate information on FP use for their National Health Information System. Including private pharmacies in FP service provision would require training staff on data management and establishing data management systems to transfer that data for inclusion in the National Health Information System; and
- The pharmacy professional associations and Department of Pharmacies and Medicine will need to add FP to existing monitoring and supervision systems. They will also need to coordinate with the local health districts to build their capacity in FP and ensure they incorporate the private pharmacies in their activities which will require time and resources.

\section{Discussion}

The provision of FP services by private pharmacies varies throughout the world. In some countries, particularly in Asia and to a lesser degree in Africa, pharmacies are already playing a major role. In other countries, such as Senegal, their role is limited but they are already providing information and services beyond the sale of contraceptives.

In Senegal, pharmacies' minor role in FP service provision results from a lack of training, logistical constraints, and above all, from a legal and regulatory environment that is not conducive to their involvement. To help the Government of Senegal achieve its national objective and honor its international FP and $\mathrm{RH}$ commitments, involving private pharmacies in the provision of FP services is imperative. The World Health Organization endorses task-shifting (particularly at the community level) to contribute to the accessibility of services: private pharmacies today have a very important role to play.

Pharmacies are often the population's first point of contact with the health system. Including private pharmacies in FP service provision will increase women's and couples' access to information and services, which would help the country to meet its FP 2020 goal of an mCPR of 45\%. Senegal is an optimal position as there is sufficient support from key FP stakeholders support strengthening the role of private pharmacies in FP.

\section{Recommendations}

To effectively capitalize on existing opportunities, and address the obstacles and challenges facing private pharmacies in the provision of FP services, the research team consulted with stakeholders to develop the following recommendations. 


\section{Government of Senegal/MHSA}

- Support advocacy efforts to establish a legal and regulatory framework for the provision of FP services by private pharmacies.

- Continue discussions with stakeholders (MHSA including DRHCS, Directorate of Pharmacy and Medicines, National and Regional Supply Pharmacies, National Council for the Order of Pharmacists of Senegal, Pharmacist's Union, importers/distributors, Alliance of Private Health Sector, technical and financial partners, etc.) on ways to remove barriers for pharmacy participation in FP services provision.

- Adapt the relevant Policies, Norms, and Protocols to consider the provision of FP services by private pharmacies.

- Include a specific module on FP and contraceptive technologies in pharmacist training curricula.

- Implicate private pharmacies in the health system (guidelines for the provision of FP services; and National Health Information System data collection and management tools).

- Provide counseling tools and materials to pharmacies.

- Conduct a study to assess provision of FP services by private pharmacies.

- Establish a monitoring system in coordination with the health districts.

\section{The Order of Pharmacists and the Pharmacist's Union}

- Support advocacy efforts, in collaboration with other key actors, to establish a legal and regulatory framework to better include pharmacy staff in the provision of FP services.

- Contribute to the development of a supervision and technical support system for private pharmacies in FP provision.

- Require pharmacists to provide adequate space for the provision of FP services.

- Provide technical input for the development of FP training tools for pharmacists.

\section{Pharmacists}

- Establish a private counseling area in accordance with FP service-provision standards.

- Participate in FP training and refresher sessions to maintain product counseling and administration skills.

\section{Technical and Financial Partners}

- Support the implementation of a study to demonstrate the provision of FP services by private pharmacies.

- Provide technical assistance to support evidencebased advocacy efforts to achieve policy changes in the provision of FP services by private pharmacies.

\section{Conclusion}

The lack of participation by private pharmacies in FP service provision results from a restrictive legal and regulatory environment, and persistent nonlegal constraints in Senegal. Results from this study suggest pharmacies could facilitate access to modern contraceptive methods throughout the country. The involvement of private pharmacies in FP services must become a reality, in accordance with Senegal's national and international commitments, the 3D Approach,5 and other de-medicalization recommendations. Furthermore, the World Health Organization endorses task-shifting of specific FP services to nonmedical staff. This has been shown to work in Senegal and other West African countries. In the drive for continued efforts to promote this promising high-impact practice, strong and urgent advocacy is needed to increase the role of pharmacists to improve access to FP services. Involving private pharmacies in FP is acceptable to clients, stakeholders, and pharmacists themselves, provided the barriers are removed. The next step is a study to assess the feasibility of private pharmacy provision of those services.

$53 \mathrm{D}=$ "Democratization, Demedicalization, Decentralization" approach underpinning the 2012-2015 NAPFP and the 20162020 NSFFP. 


\section{REFERENCES}

Agence Nationale de la Statistique et de la Démographie (ANSD) [Sénégal] et ICF International. 2012. Enquête Démographique et de Santé Continue (EDS-Continue 2012-2013). Calverton, Maryland, USA: ANSD et ICF International

Agence Nationale de la Statistique et de la Démographie (ANSD) [Sénégal], et ICF. 2016. Sénégal : Enquête Démographique et de Santé Continue (EDS-Continue 2015). Rockville, Maryland, USA: ANSD et ICF International FALL, C. and M.M. DIOP. 2015. Enquête sur la planification familiale dans les pharmacies du milieu urbain au Sénégal. MSAS/FHI. Rapport d'analyse, Novembre 2015.

Fall C., Diop M. M. 2015. Enquête sur la planification familiale dans les pharmacies du milieu urbain au Sénégal 2015. Rapport d'analyse, novembre 2015

Hotchkiss et al. 2011. "Effect of an expansion in private sector provision of contraceptive supplies on horizontal inequity in modern contraceptive use: Evidence from Africa and Asia." International Journal for Equity in Health.

Mane, B., S. RamaRao, M. Brady, F.B. Mbow, and B. Thiam. 2012. Attitudes, croyances et pratiques des leaders d'opinion clés (LOC) et des prestataires sur la contraception d'urgence (CU) au Sénégal. Population Council.
Mbow, F.B., N. Diop, and N.D. Fall. 2017. “Exploration du rôle potentiel des pharmacies privées dans l'offre de services de planification familiale au Sénégal-Revue documentaire sur les aspects juridiques." Project Brief. Dakar, Sénégal: Population Council, Le Projet Evidence.

Diaby, A., F.B. Mbow, M. Sall, and S. Chace Dwyer. 2017. “Exploration du rôle potentiel des pharmacies privées dans l'offre de services de planification familiale au Sénégal-Revue documentaire sur les aspects non-juridiques." Document de Travail. Dakar, Sénégal: Population Council, Le Projet Evidence.

Mbow, F.B., A.K. Diallo, N. Diop, S.M. Kane, C.S.B. Sarr, and S.Chace Dwyer. 2017. "Exploration du rôle potentiel des pharmacies privées dans l'offre de services de planification familiale au Sénégal-Analyse secondaire des données de ADEMAS." Document de Travail. Dakar, Sénégal: Population Council, Le Projet Evidence.

Mbow, F.B., N. Diop, S. Chace Dwyer, F. Ndiaye, and B.M. Daff. 2017. “Exploration du rôle potentiel des pharmacies privées dans l'offre de services de planification familiale au Sénégal-Recherche qualitative." Document de Travail. Dakar, Sénégal: Population Council, Le Projet Evidence.

Plan d'Action National de Planification Familiale 2012-2015. République du Sénégal. Dakar, Sénégal: MSAS.

\section{USAID}

The Evidence Project is made possible by the generous support of the American people through the United States Agency for International Development (USAID) under the terms of cooperative agreement no. AID-OAA-A-13-00087. The contents of this document are the sole responsibility of the Evidence Project and Population Council and do not necessarily reflect the views of USAID or the United States Government.

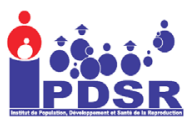

The Institute of Training and Research of Population Development and Reproductive Health of the University of Cheikh Anta Diop was created in 2000-2001. The institute's goal is to reinforce knowledge of the interdependence between health, population and development in Africa. IPDSR implements and promotes interdisciplinary pedagogical models and research.

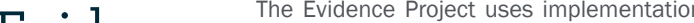 science-the strategic generation,} translation, and use of evidence-to strengthen and scale up family planning and reproductive health programs to reduce unintended pregnancies worldwide. The Evidence Project is led by the Population Council in partnership with the Population Reference Bureau.

S The Agency for Social Marketing Development 1 ADEMAS is a Senegalese non-profit organization created in June 1998. ADEMAS works to develop socia programs intended to influence the voluntary behavior of target groups, for the improvement of the population's well-being and quality of life.

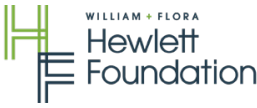

The William and Flora Hewlett Foundation is a non-partisan, private charitable foundation that advances ideas and supports institutions to promote a better world.

\section{The Evidence Project}

Population Council

Sacré Cœur Pyrotechnie

Appartement 2ème Etage à Droite

Dakar, Sénégal

21027 Dakar Ponty

tél: +221.33.859.5300

evidenceproject@popcouncil.org
Recommended Citation: Mbow, Fatou Bintou, Sara Chace Dwyer, and Nafissatou Diop. 2018. "Exploring of the Potential for Private Pharmacies to Provide Family Planning Services in Senegal." Synthesis Brief. Dakar, Sénégal: Population Council, Evidence Project

(c) 2018 Population Council, Inc.

For more information, contact Fatou Mbow at fmbow@popcouncil.org 